\title{
When Actions Feel Alien—an Explanatory Model
}

\author{
Timothy Lane
}

\begin{abstract}
It is not necessarily the case that we ever have experiences of self, but human beings do regularly report instances for which self is experienced as absent. That is, there are times when body parts, mental states, or actions are felt to be alien. Here, I sketch an explanatory framework for explaining these alienation experiences, a framework that also attempts to explain the "mental glue" whereby self is bound to body, mind, or action. The framework is a multidimensional model that integrates personal and sub-personal components, psychological and neural processes. I then proceed to show how this model can be applied to explain the action-related passivity experiences of persons suffering from schizophrenia. I argue that a distinctive phenomenological mark of these experiences is that they are vividly felt, unlike ordinary actions (those taken to belong to self), and I seek to explain these heightened sensory experiences from within the proposed framework. I also propose hypotheses concerning such phenomena as thought insertion and anarchic hand syndrome that are motivated by this framework. Finally, I argue that the proposed model and view of self-experiences is consistent with several aspects of and theories of consciousness, especially theories which indicate that consciousness is more likely to be engaged when we are dealing with novelty or error-e.g., when self seems to have gone missing. I conclude by recommending that if we wish to learn about self, we would be well advised to attend closely to those times when it seems absent.
\end{abstract}

"The self is an absence..." (Sorensen 2007, p. 450)

"...we can feel the absence of the self...but not the presence of the self." (Prinz 2012a, p. 148)

\section{Introduction}

It is not obvious that we ever have experiences of self, nor is it obvious that there is any such entity that is properly regarded as a self. But human beings do regularly report instances for which self is experienced as absent. That is there are times when body parts, mental states, or actions seem to be alien. In somatoparaphrenia,

T. Lane $(\bowtie)$

Graduate Institute of Humanities in Medicine, Taipei Medical University, Taipei, Taiwan e-mail: timlane@tmu.edu.tw

Tzu-Wei Hung (ed.), Communicative Action, DOI 10.1007/978-981-4585-84-2_4,

(C) Springer Science+Business Media Singapore 2014 
an arm, despite being attached to the body, is experienced as belonging to someone else. In schizophrenia, a thought, despite only being reportable from the first-person perspective, seems not to belong, to have been inserted into the stream of consciousness. And, in anarchic limb, an arm performs actions that do not belong to self, actions that feel alien.

Collectively, these and numerous other phenomena suggest that Prinz and Sorensen, who are quoted in the epigraph, have identified a key characteristic of self, or at least an important issue concerning the nature of epistemic access to self. It is known more by its absence than by its presence. In ordinary circumstances, there may not be any self-experiences or "I-qualia" at all (cf. Prinz 2012b, p. 214). But when subject to an illusion or suffering from pathology, persons do sometimes have vivid experiences that self is absent.

The purpose of this essay is to extend a line of thought begun previously (Lane 2012): that is, these various alienation experiences can be explained from within a unified framework. The "mental glue" (Klein 2013a, p. 90) in virtue of which self is bound to its body, its mental states, and its actions is all or largely implicit. When this relationship is "unstuck" is when we experience the absence of self. ${ }^{1}$ The thesis extended here is that absence experiences just are the meta-awareness (MA) that components of experience are clustering in atypical ways, even though those experiences are being processed on a sub-personal level as highly self-related. Here it is argued that action alienation is, at least in part, explainable in these terms.

\section{Problems of Belonging}

Previously I (cf. Gallagher 2012, pp. 207-211; Lane and Liang 2011) have argued that even when only one person is positioned to introspect ${ }^{2}$ on or report a mental state, it should never be presupposed that the mental state belongs to that person. "Belonging," or what I have elsewhere referred to as "mental ownership" (Lane and Liang 2010), is always a contingent relationship. This is not to say that mental states or conscious experiences can fly about untethered, as though they were baseballs. Clearly, mental states are more like dents than baseballs, in that they cannot exist on their own. But to say that some organism must host them is one thing; to say that

\footnotetext{
${ }^{1}$ There is something potentially misleading about talk of a relationship between self and body parts, mental states, or actions. Talk of belonging or mental glue in such contexts suggests a twoplace relation, which is not the case, at least not if one of the relata is taken to be an experience of self (cf. Prinz 2012b, p. 231). Although for expository purposes I do write in such a way that a relationship of this type might seem to be implied, as I explain below, "self" here is taken to be a distinctive type of neural activity, not an experience in and of itself. What Baars et al. (2003) and Baars (2007) metaphorically refer to as the brain's "observing self" is a useful way to think of this relationship.

2 Throughout this manuscript I use "introspection" in what Shoemaker (1994, p. 258) dubs the "humdrum" sense, referring to information we have access to that is expressed in such remarks as "it itches," "I'm thirsty," and so forth.
} 
they necessarily belong to the self who introspects upon and reports them is something else again (Klein 2013a, p. 90; Lane 2012, p. 260).

Cases of craniopagus twins can usefully illustrate the belonging relationship (e.g., Stone and Goodrich 2006). A very recent case involves two sisters who are connected at the head in a manner that forces them to face away from one another (Bor 2012, pp. 28-31). It seems that a neural bridge connects their thalami, ${ }^{3}$ and that this connection makes it possible for them to have some degree of joint access to sensory processing: for example, one girl will introspectively sense the thirst of her sister and proceed to reach for a cup of water that she hands to her conjoined sibling. In effect, when such sharing occurs, each of the siblings is able to distinguish between those sensations "that belong to self and those that belong to her sister" (Bor 2012, p. 29). ${ }^{4}$ In other words, one sibling might have taste, tactile, or visual sensations that belong exclusively to her. But the other sibling can become aware of these sensations via introspection. The latter sibling though, despite having this seemingly direct access to the sensations does not feel that they belong to her. The mental glue is absent.

Succinctly, problems of belonging (POBs) are those instances wherein from the third-person perspective a body part, a mental state, or an action would seem to belong to a given person, but from the first-person perspective the experience is of alienation. As mentioned previously, somatoparaphrenia, schizophrenic thought insertions, and anarchic limb are all instantiations of belonging's absence. But POBs can also occur in the reverse condition: that which from the third-person perspective could not possibly be said to belong is experienced as belonging. When the rubber hand illusion is successfully induced, a detached, artificial hand is experienced by the participant as belonging to self (e.g., Lane et al. 2013). When thought and behavior are manipulated in certain ways, as in "I Spy" experiments (Wegner 2002, pp. 74-78), ${ }^{5}$ actions performed by someone else are felt to have been performed by self. And in cases of synesthesia for pain, the usual self-other distinction that enables us to experience empathy without literally experiencing what is felt by others, collapses, such that what we observe in others triggers pain that belongs to self (Fitzgibbon et al. 2010). In short, POBs do not occur in quotidian circumstances; instead, they are associated with pathology, illusion, or other atypical phenomena.

Lane (2012) and Klein (2013a, b) have described a variety of cases of different types, wherein $n=1$, that illustrate POBs. These include, for example, instances of visual sensations and episodic memory. In both cases, the person who is uniquely situated to report on these experiences reports that they seem not to belong to self. For the case of vision, visual states are not immediately taken as belonging to self (Zahn et al. 2008). There is a time lag between initial awareness and subsequent relating of the images to self. In the case of episodic memory, memories that sat-

\footnotetext{
${ }^{3}$ The thalamus projects a large number of axons to all parts of the cortex; the cortex projects an even greater number of axons to the thalamus (Jones 2007).

${ }^{4}$ Italics not contained in the original.

${ }^{5}$ These experiments attempt to capture, under controlled conditions, certain aspects of what persons experience when they play with an Ouija board.
} 
isfy all the conditions for counting as episodic are felt not to belong to self (Klein and Nichols 2012), despite the fact that episodic memories are typically taken to be uniquely self-involving. Although the total number of recorded cases is small, it might be that they are underreported, because they are so counter-intuitive, and because natural language was not designed to express such aberrancies (Lane 2012, p. 259; Klein 2013a, p. 101, b, p. 11). In the interest of both focusing attention on these phenomena, and in order to introduce POBs as they are related to action, an explanatory model is adumbrated in the next section.

\section{An Explanatory Model of Belonging}

If we take cases for which, from the third-person perspective, there is no doubt but that mental states are realized in virtue of a person's brain (along with endocrine and immune systems, as well as spinal cord) activity, but that the person describes experiencing those states as alien or estranged, as belonging to someone else, pain asymbolia can serve as paradigmatic of POBs. Typically when pain states are experienced, sensory-discriminative and affective-motivational aspects are conjoined (Auvray et al. 2010). In other words, not only is a person able to identify such discriminate features of pain as its qualitative character (e.g., cramping, shooting, stabbing, or burning), location, duration, and intensity, those features are intimately — what might seem to be intrinsically — associated with suffering and aversive reactions. In the normal course of events that is, the sensory-discriminative and the affective-motivational are experienced as a whole, faithfully reflecting what we mean when we say "I am in pain" - it hurts and we desire relief.

But in cases of pain asymbolia, the sensory-discriminative and the affectivemotivational dissociate (Grahek 2007, pp. 51-71), a dissociation that is often associated with lesions to the parietal operculum and the posterior insula. Here, although persons so afflicted are able to report pain sensations, they also report being unbothered. That they are not bothered is confirmed by the absence of withdrawal behaviors, an easy willingness to cooperate with pain testing, and the inability to learn appropriate avoidance behaviors, despite normal perception of both deep and superficial pain (e.g., Berthier et al. 1988, pp. 42-43). In such persons pain is, so to speak, shorn of its painfulness.

Pain shorn of its painfulness can occur because our pain system bifurcates: the path that engages the affective-motivational projects to the limbic system, while the path that enables fine sensory discrimination projects to the cortex. In some cases, the effects of such disconnection can be so profound that patients do more than report not being bothered, not experiencing painfulness. Some patients report acute awareness of sensory-discriminative aspects of pain, as well as the feeling that those introspectively accessed pain sensations "seem to belong to someone else, not to me" (Sierra 2009, p. 150). ${ }^{6}$

${ }^{6}$ Somewhat similar reactions to pain have been reported for those who have undergone surgical ablation of pathways linking the thalamus with parts of the frontal lobes (Klein 2013a, pp. 91-93). 
Fig. 1 Principle of confounded expectations: the case of pain asymbolia (Reprinted with permission of Springer Science+Business Media, from Lane, T. (2012).

Toward an explanatory framework for mental ownership. Phenomenology and the Cognitive Sciences, 11, 251-286)

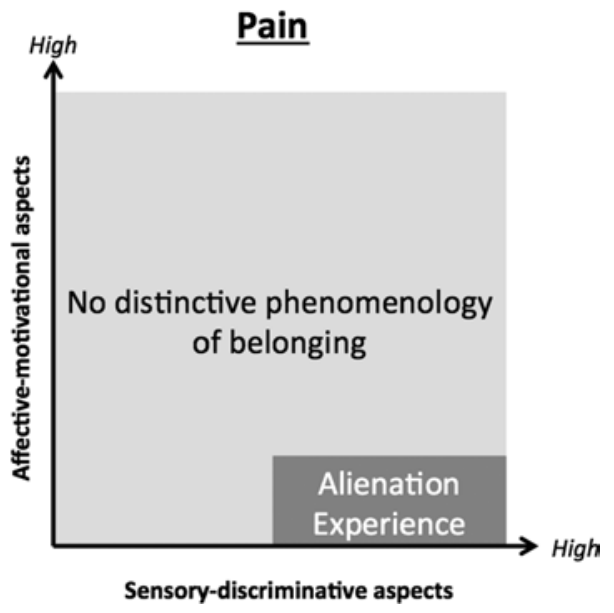

Figure 1 delineates this relationship. Under normal conditions, those tacitly assumed, whenever sensory-discriminative aspects of pain are vividly felt, so too are the affective-motivational aspects. To abstract away from this particular case, we could say that this phenomenon is an instantiation of a general principle, what I refer to as mental state clustering (MSC). That is to say, mental states are not experienced in isolation, but that they cluster is something we do not notice until something goes amiss. ${ }^{7}$

Here the affective-motivational aspect of pain has gone missing, as is indicated by the $y$-axis. This confounding of tacit expectations aptly illustrates what I refer to as the principle of confounded expectations (PCEs). One interpretive option available to the person whose expectations are confounded in this way is that the pain states do exist, but that they do not belong to self.

Such characterization of pain should not surprise, because the neural substrates for self-pain and other-pain are distinct (Ochsner et al. 2008, p. 153). One region in particular is worth noting: a large portion of the mid-insula that is posterior to the region activated in common for both self- and other-pain (Ochsner et al. 2008, p. 153) evinces distinctively higher levels of activation for self-pain. Since pain asymbolia is often associated with lesions to the posterior insula, from the firstperson perspective it might be a perfectly reasonable inference to attribute the pain sensation to "someone else."

At least one comprehensive theory of the brain seems broadly consistent with the notion of PCE. In its essence, the idea is that brains are hypothesis-testing machines dedicated to minimizing the error of their predictions about sensory input

\footnotetext{
${ }^{7}$ Instances of mental states failing to cluster in tacitly expected ways are plentiful. To cite just one other example, those who suffer from motion blindness have otherwise normal visual experiences of the external world, but their ability to perceive motion is greatly impaired (e.g., Zihl et al. 1983). Typically visual perceptions of color and shape cluster with motion. But in these rare cases, clustering fails.
} 
received from the world (Clark et al. 2013; Friston 2009; Hohwy 2013) or from the body (Seth et al. 2012). If the brain is just such a machine, prior probabilities would lead it to predict standard clustering. But when such predictions or expectations are repeatedly confounded by sensory inputs, in order to minimize prediction error, the brain would generate novel hypotheses. In this case, the pains belong to someone else. Although this would not be literally true, at least not in the sense that the pains were being realized in someone else's body, assuming that the posterior insula lesions remain as they are, there might not be sensory inputs of the right sort to bring about further adjustment in the brain's hypothesis.

But even if brains are hypothesis-testing machines, MSC and PCE could not be sufficient to explain POBs. To illustrate with one respect in which these will need to be augmented, consider the difference between pain asymbolia and Capgras syndrome. In the former, patients are aware of pains that seem not to belong to self; in the latter, patients are aware of familiar faces that seem oddly alien (Bortolotti 2010, pp. 68-73). As is the case with pain asymbolia, Capgras syndrome is sometimes explained as a confounding of expectations, something having been left out. As with pain asymbolia, what is left out is expected, affective response (Ellis and Lewis 2001).

Although both syndromes involve PCE, only pain asymbolia is relevant to POB. Capgras syndrome concerns not what belongs to self, but what is familiar to self. Accordingly, an explanatory framework adequate to handle POBs requires some means of distinguishing that which belongs to me from that which is familiar to me. Fortunately, recent discoveries concerning self-related processing (SRP) at the neural, sub-personal level enable the making of such a distinction.

For more than a decade, Northoff (e.g., 2013a, p. 79; 2013b, pp. 255-256) has been documenting ways in which the brain's cortical midline structures (CMSs) ${ }^{8}$ and the subcortical midline structures (Northoff and Panksepp 2008) are involved in determining whether perceptual stimuli are self-related. Employing fMRI, EEG, and MRS, he and his research team have identified certain regions of interest as well as patterns of electrical and biochemical activity that enable us to distinguish between those stimuli that are and those that are not self-related. Of special relevance here are the results of a metaanalysis (see Fig. 2), which show that at the neural level we distinguish among those stimuli that are self-related (e.g., one's own name or face), those that are familiar (e.g., names or faces of close family members), and those that are neither, the other condition (e.g., names or faces of well-known, but not familiar, people). Several regions seem to be implicated in SRP, and much less so in the familiar or other conditions (Northoff 2013a, pp. 258-259; Northoff and Qin 2011). Especially noteworthy in this regard is the perigenual anterior cingulate cortex.

How then might MSC, PCE, and SRP be combined within an explanatory framework, so as to enable distinguishing phenomena related to belonging from

\footnotetext{
${ }^{8} \mathrm{CMS}$ regions include the perigenual anterior cingulate cortex, the dorsomedial prefrontal cortex, and the posterior cingulated cortex. The CMS overlaps with Feinberg's (2009, pp. 152-155) "integrative self-system" and with the default-mode network (Raichle 2010), which has also been implicated in self-referential processing.
} 


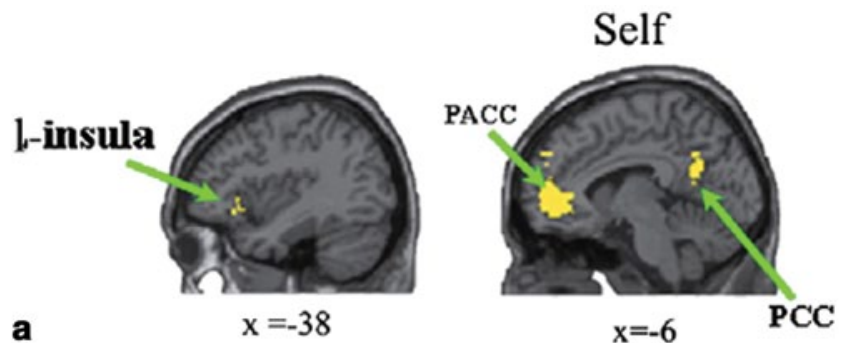

b

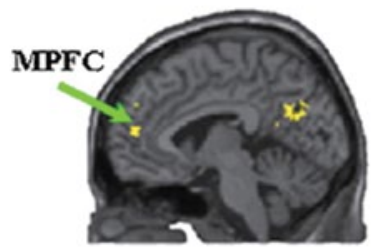

$x=-4$

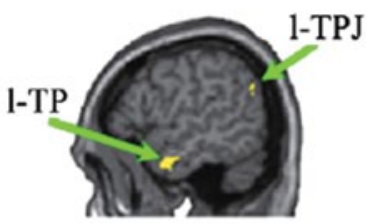

$x=-54$

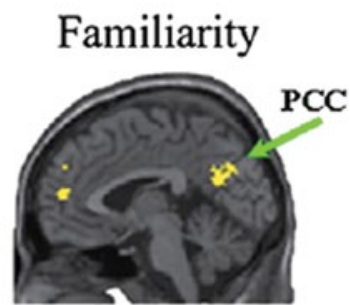

$x=-2$

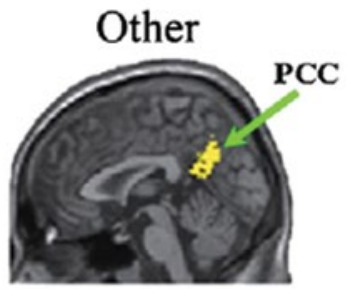

$x=2$

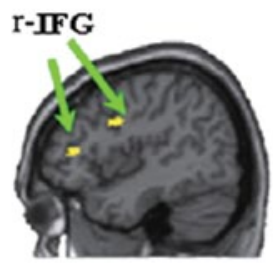

$x=46$

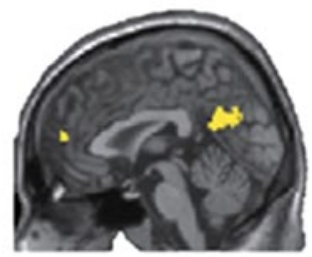

$\mathrm{x}=2$

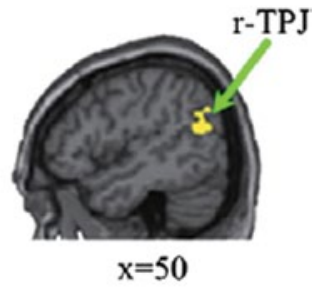

Fig. 2 The activated clusters for three conditions: self (a), familiarity (b), and other (c), based on a multilevel kernel density analysis. $M P F C$ medial prefrontal cortex, $P A C C$ perigenual anterior cingulate cortex, $P C C$ posterior cingulate cortex, $l$-TP left temporal pole, l-insula left insula, $l$-TPJ left temporoparietal junction, $r-T P J$ right temporoparietal junction, $r-I F G$ right inferior frontal gyrus (Reprinted with permission of Elsevier, from Qin, P., Northoff, G. (2011). How is our self related to midline regions and the default-mode network? NeuroImage, 57(3), 1221-1233)

phenomena related to familiarity or to other conditions? The confounding of expectations can be illustrated by a simple 2-D model, as with Fig. 1 previously. But in order to distinguish among different types of confounded expectations, we need to add a third dimension, as is depicted in Fig. 3.

Indeed, the framework need not be restricted to explaining self or familiar experiences. It can even be extended to include other phenomena as, for example, derealization, the feeling that one is cut off from the outside world, that it seems "unreal" (Sierra 2009, pp. 38, 39). Articulate patients frequently ascribe the feeling of "unreality" to the absence of affective coloring. They describe the world as seeming distant, flat, or artificial. If the loss of affect, or its distortion, is a significant component of de-realization, then the model proposed here seems capable of explaining a spectrum of phenomena that includes self, familiar, and other experiences. 


\section{3-D Model of Belonging}

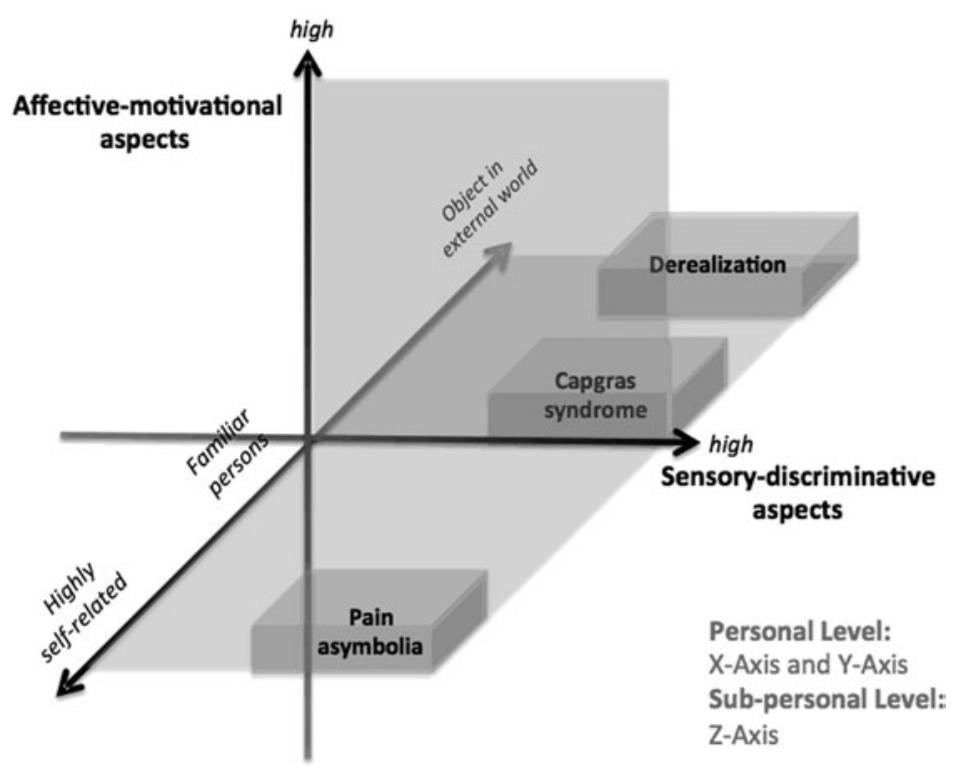

Fig. $3 z$-axis added to model to illustrate role of sub-personal, self-related processing

This framework is not just a post hoc reconstruction. It suggests lines of inquiry when new instances of POB are encountered. For example, recall the case of episodic memory reported by Klein and Nichols (2012). In this instance, the memories satisfy all conditions for counting as episodic, yet they are felt not to belong to self. A prediction motivated by this model is that if we encounter another case of this type, we should investigate to determine whether the patient is experiencing loss of affect, perhaps caused by lesions similar to those observed in cases of pain asymbolia, while SRP remains intact.

Some philosophers (e.g., McDowell 1994) have expressed reservations about mixing personal and sub-personal elements within the same explanatory framework. The personal level of description involves, inter alia, description of conscious mental states and the subjects who experience those states; the sub-personal level, on the other hand, involves the mechanistic explanations of the objective sciences, including explanations of the sort invoked here, those that make reference to brain regions and patterns of electrical and biochemical activity (cf. Davies 2000; de Pinedo-Garcia and Noble 2008). But because my concern in proposing this framework is to suggest testable hypotheses (cf. Crick and Koch 2003, p. 119) and to make predictions concerning heretofore unexamined phenomena (cf. Hempel 1965, p. 365), what matters is whether or not the framework does indeed prove fruitful.

What is more, empirical discoveries that connect sub-personal properties to the personal level can diminish worries about seemingly mongrel approaches to explanation (Shea 2013). In the matter at hand, the relevant empirical discoveries involve 
judgments as regards whether or not a stimulus (visual, auditory, etc.) is self-related. A growing body of evidence suggests that these judgments can be predicted based upon either pre-stimulus neural activity or post-stimulus neural activity that occurs before subjects have conscious experience of the stimuli (e.g., Northoff 2013a; Northhoff et al. 2014). In other words, empirical studies suggest that a point of contact between sub-personal properties - neural activity in anterior CMSs - and the personal level— judgments concerning self-relatedness - has been identified.

Still, even after incorporating the $z$-axis, two problems remain. First, the $x$ - and $y$-axes are only one example of confounded expectations. In the case of pain asymbolia, "pains" that do not hurt are experienced, contrary to what is normally expected of pain. But expectations can be confounded in multiple ways, even if we assume that the experiences are highly self-related. So here the problem does not just concern distinguishing among self, familiar, and other. There is a need to distinguish among the different ways in which mental states can cluster.

This point will be developed in more detail in the next section, when action is treated in some detail. But to illustrate briefly another way in which expectations can be confounded, consider the case described by Zahn et al. (2008) that was mentioned previously. Here, the person who reports visual states describes them as not immediately experienced as belonging to self. Instead, there is a time lag between initial awareness and subsequent relating of the images to self, and this description of the patient's phenomenology seems to be at odds with standard definitions of phenomenal consciousness. Carruthers (2000, p. 14), for example, defines phenomenally conscious events as "ones that we recognize in ourselves, non-inferentially, or 'straight off,' in virtue of the ways in which they feel to us, or the ways in which they present themselves to us subjectively." Similarly, Rosenthal (2002, pp. 408422,2005 , pp. 343, 344) describes conscious mental states as feeling "direct," "unmediated," or "noninferential."

The case of visual sensations delayed seems to be an instance of phenomenally conscious events that confound expectations concerning how mental states of this type should be experienced. That is they seem not to be straight off, direct, or unmediated. These characterizations of normal conscious experience do not necessarily imply that there should be no time lag, but they suggest as much. And other examples from the empirical literature also suggest that time is a critical factor, that we expect immediacy.

Sass and Parnas (2003, p. 438) describe a patient suffering from schizophrenia whose experiences are illustrative. The patient "reported that his feeling of his experience as his own experience only 'appeared a split-second delayed'." Although the pathologies are distinct, the mode of describing the experience of conscious experience is similar. The implication I derive from these cases and the standard philosophical characterizations of conscious experience is that the latter are informed by quotidian cases, those upon which our expectations are based. In other words, philosophical intuitions accurately capture normal human expectations. But these aberrant cases show that immediacy is not a necessary condition for conscious experience, and that when there is a time delay a POB is reported. 
The characterization of POBs thus far given and the implications of PCE, however, suggest two respects in which the model must be elaborated. First, since expectations can be confounded in different ways, it must be the case that the $x$ - and $y$-dimensions can have different contents. That is, awareness of different types of atypical MSC can yield POBs. Therefore, a more comprehensive model must allow for such variability among the $x$ - and $y$-dimensions.

Moreover, atypical clustering of mental states accompanied by sub-personal determinations of the degree of self-relatedness could not be sufficient to explain POBs. For POBs to occur, expectations must be confounded, expectations about how lower level mental states should cluster. In other words, to take the case of pain asymbolia as an example, not only must there be an awareness of the sensory-discriminate contents of pain, there must be an MA that something - the affective-motivational aspects - are missing. The same would be true for instances of temporal lag.

Meta-awareness, or meta-consciousness, is a process whereby individuals "take explicit note of the current contents of consciousness" (cf. Schooler et al. 2011, pp. 319, 321). In cases of POB, one becomes meta-aware that the contents of consciousness are clustering in atypical ways. It should be noted that this incorporation of meta-mental states is not the same as meta-cognition that is employed in higher-order thought (HOT) theories of consciousness (e.g., Lau and Rosenthal 2011; Rosenthal 2005). The difference is that in HOT theories, the lower level states are not presumed to be conscious in the absence of the meta-level; the meta-level is a necessary condition for conscious experience to obtain. Indeed, according to HOT theories, it is even the case that lower-level states are unnecessary (Lane and Liang 2008). Here, however, MA is becoming aware of lower-level mental states that are not dependent upon the meta-level in order for them to be conscious experiences.

The complete model can then be depicted as in Fig. 4. Here, in this 4-D model, the $x$ - and $y$-axes of the original 3-D model are collapsed into one dimension, the MSC. This adjustment provides three benefits: one, it allows for an unlimited variety of distinct types of mental clustering. Two, it allows for the possibility that clustering differs by degree, ranging from the routine to the bizarre. And, three, it allows for the likelihood that clustering should not be thought of merely as a 2-D phenomenon. The sensory-discriminative and affective-motivational example depicted in Fig. 1, as well as the example of action alienation to be presented below, might seem to suggest that for MSC one need only consider two dimensions. But there is no empirical reason to believe that two dimensions are adequate to cover all instances of POB.

As for the sub-personal level, here identified as SR, nothing is changed. As is the case with the 3-D model, it indicates the degree to which a sensory input is assessed as self-related. MA is new to this version of the model. Here too, difference is by degree, and it might be just as much the result of high-level as lower-level activity. The example of alienation described by Sass and Parnas (2003) that was presented previously can illustrate the greater involvement of higher level activity. They explain the delay in the psychotic patient's report of a delay in feeling experiences to be his own as due 


\section{Alienation and Belonging Experiences}

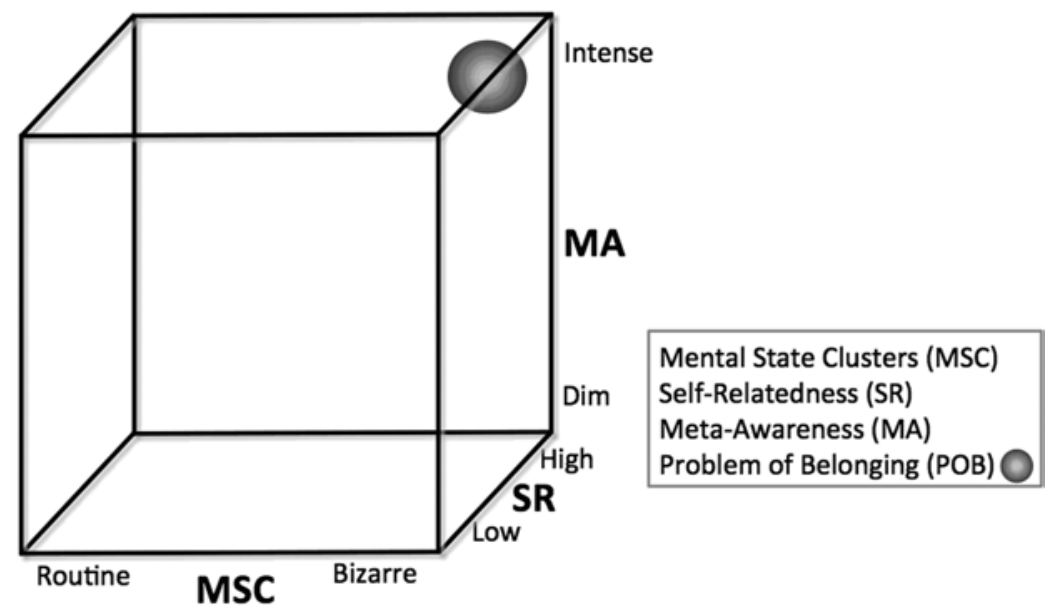

Fig. 4 Cube Model of Belonging: Note that the $x$ - and $y$-axes of Figs. 1 and 3 are here collapsed into one dimension, $M S C$. This is done in order to suggest how the model can accommodate diverse phenomena and how it can handle more than three dimensions

to "hyper-reflexivity," an exaggerated form of "self-awareness." Although I would not characterize this phenomenon in just these terms, the idea of hyper-reflexivity suggests that perhaps experienced bizarreness of lower-level experiences can be made more salient by especially intense degrees of mental awareness. For this example of psychosis then, perhaps it is MA that drives the experience of alienation. On the other hand, for pain asymbolia, perhaps it is the MSC that drives the experience, as is the case with popup perceptual illusions. In other words, the model allows for the empirical possibility of POBs that are driven by either top-down or bottom-up processes.

An additional virtue of this model is that it accounts for both alienation and belonging experiences (Lane et al. 2013). As for the latter, in the case of the rubber hand illusion, subjects become aware of the bizarre clustering of mental states - tactile sensations are experienced as being where they could not be. It is in becoming intensely aware of that "touch referral," which is likely a combination of top-down and bottom-up processes, that subjects begin to experience a rubber hand as belonging to self.

For all types of POB, whether alienation or belonging, MSC, MA, and SR are required. As depicted in the cube model, when MSC is bizarre, MA is intense, and $\mathrm{SR}$ is high, a POB will result. Within this conceptual space, the POB is identified by the dot in the rear, upper right-hand corner. 


\section{Alien Actions and the Explanatory Model of Belonging}

Among the several symptoms of patients suffering from schizophrenia are passivity experiences or delusions of alien control. The essence of this symptom is the experience of one's will as having been replaced by some other force or agency (Blakemore et al. 2000b, p. 1132): patients often describe their thoughts, speech, or actions as being controlled by external agents, such as spirits or machines. Such experiences are not necessarily specific for or diagnostic of schizophrenia, but most published reports of these experiences concern people who are suffering from schizophrenia (Nordgaard et al. 2008).

There is no question but that it is the patient's brain or body that hosts the thoughts, speech, or actions, but the experience of belonging is disturbed. As regards action, the principal focus of this section, many instances are decidedly unremarkable, concerning such trivial things as combing one's hair or typing on a computer keyboard. Mellor (1970) provides some representative examples: "My fingers pick up the pen, but I don't control them. What they do is nothing to do with me." Frith et al. (2000, p. 18) provide others that include some commonplace sources of alien agency: "My grandfather hypnotized my brain and now he moves my foot up and down." "They inserted a computer in my brain. It makes me turn to the left or right."

It should be noted that many authors who describe these symptoms distinguish between agency and ownership. Hirjack and Fuchs (2010, p. 100), for example, describe a patient who experienced bodily movements as "being made, controlled, and steered by outside forces." Nevertheless, according to Hirjack and Fuchs, the experience of these bodily movements as "belonging to himself was still preserved." In other words, agency is aberrant, but some form of ownership seems intact. This distinction, though commonly invoked in discussions of the experience of schizophrenic passivity experiences, has recently been challenged (Bayne 2010, pp. 156-162; Lane 2012, pp. 279-280; Martin and Pacherie 2013). This debate, however, need not detain us here. It is sufficient that there is a consensus that agency for, or authorship of, the movements is experienced as not belonging to self.

One important respect in which ordinary action differs from alien action is that the experience of action-related sensations is less vivid in the former than in the latter. Frith $(2005$, p. 752), commenting on this difference, has observed that "the normal mark of the self in action is that we have very little experience of it." But most philosophers and scientists seem to presuppose ordinary action is accompanied by a distinctive sensory experience of some sort. Bayne (2011, p. 356), citing the example of waiting tables, claims that "as you pour the water, you experience yourself as an agent. You experience yourself as someone who is doing something." And, Kühn et al. (2013, p. 1936) claim that we frequently do "make instrumental actions where we have a definite background feeling or buzz of being in control."

Although I incline to the position that ordinary actions are silent, ${ }^{9}$ for purposes of the ideas developed here, following Frith, it is sufficient to allow that the conscious

\footnotetext{
${ }^{9}$ I will not develop my reasons in detail, but I submit that part of the confusion in this vicinity is due to a failure to distinguish clearly and consistently between "qualitative" psychological states, like perceptions and sensations, and "non-qualitative" states, like beliefs or desires (cf. Rosenthal
} 
experience of ordinary and alien action differs. In this spirit, we might then say that ordinarily the phenomenology of self in action is "thin" (Metzinger 2003; Tsakiris et al. 2007, p. 645), while the phenomenology of alien actions is "thick." "Thin" here might, at least in part, be understood as just knowing when there is negligible dwell time: "when I push a light switch I just 'know' that the light came on because of my action - that I am the author of the action and its consequent effect. There is negligible dwell time..." (Obhi and Hall 2011). Of course when we pause to reflect and render judgment that is a different matter, but here the concern is with what occurs in the nonce, while the action unfolds. And that does not seem to require thick sensory activity. But how is it that some actions are accompanied by a thick phenomenology and why are these felt to be alien?

If the model limned previously is taken as a guide, we can begin to answer these questions by observing that expectations about how mental states should cluster are confounded. The tacit expectation that action phenomenology be thin is confounded. But in virtue of what mechanism is it that what is normally thin becomes thick?

Discussions of ordinary instances of action often begin with the observation that although images on the retina change as a person's eyes move, the visual world is nevertheless experienced as stable (e.g., Churchland 2002, p. 85). Whether eye movement is due to saccades or tracking, the retina registers significant, continuous changes in light patterns. Nevertheless, because our brains interpret these changes as due to the motion of our eyes, rather than motion in the world, stable objects in the world are experienced as remaining stable. On the other hand, when objects in the world do move, our brains can distinguish that from the movement of our eyes. ${ }^{10}$ So it is that in all normal circumstances, we can distinguish self-generated movement from movement in the external world - detecting motion when it is there and not confusing it with motion derived from the activity of our eyes. How is it that the brain seems so effortlessly and reliably to make this distinction?

On one view, agents are equipped with "forward action models," so named because they can estimate desired results prior to the realization of actions (e.g., Blakemore et al. 1999; Blakemore et al. 2000a). Succinctly, simultaneous to the sending of a motor command an efference copy (a "corollary discharge") of the command is sent, a copy that makes possible prediction of the movement's sensory consequences. Predicted and actual effects (re-afferences) are then compared. When these two match, the comparator emits a signal indicating that movement is self-generated. In this way, we are able to distinguish between the motion of our eyes and motion in the world.

\footnotetext{
2005, pp. 218-219, 303-305). Bayne et al., when referring to ordinary action, seem to be writing about non-qualitative states. My position is that in ordinary action the qualitative states though are silent. That is, ordinarily, when we act, our actions are not accompanied by distinctive perceptions or sensations. As to whether ordinary actions are accompanied by distinctive non-qualitative states, that is a separate issue.

${ }^{10}$ The visual experience that objects in the world are moving, when they are actually stationary, can also be caused by gently pressing the eyeball or by paralyzing the eye with curare (Stephens and Graham 2000, p. 136).
} 
This model, as well as others that similarly emphasize congruence between predicted and actual outcomes (Pacherie 2011, p. 448), have been applied to action in general. One important aspect of these models is that they predict when outcomes match they result in "sensory attenuation." That is when predicted sensory consequences occur they are suppressed or attenuated. In other words, in the ordinary course of events, when persons regard themselves as the agent of an action, sensory consequences - proprioceptive and somatosensory sensations - of the action are not vivid. On the contrary, sensory consequences of actions not attributed to self are more vividly felt. "Conscious perception reflects only the error generated by this comparison," the degree to which predicted and actual outcomes fail to match (Voss et al. 2010). Baldly, when expectations are confounded, when proprioceptive and somatosensory sensations are felt, those actions are alien.

Sensory attenuation presupposes another dimension though. In order for this to occur, the behaviors performed or the behaviors observed must be felt to be actions attributable to an agent who harbors intentions. Intended, voluntary actions, unlike unintended, involuntary actions, evince what has come to be known as "intentional binding" (Haggard et al. 2002). "Binding" is of a temporal sort, such that the interval between actions and their consequences is experienced as shorter than is actually the case. In the standard experimental paradigm, the subjective experience of elapsed time between the act of pressing down on a key and the effect of hearing a tone is measured. Act and consequence seem to "attract" one another when the act is felt to be agentive. ${ }^{11}$ This time compression does not occur when acts are not felt to be agentive.

Importantly, intentional binding is not specific to self (Wohlschläger et al. 2003). For example, when observing human hands, we temporally bind their movements to the consequences of their movements. Intentional or temporal binding, however, does not occur when what we observe is a rubber hand pulled by a mechanical device. It seems to be the case that intentional binding occurs for both self and other, just so long as the other we observe is a potential agent (cf. Moore et al. 2013). What matters then for intentional binding are the following: (a) a basis for inferring the existence of an intention (e.g., to press a button); (b) the observation of an action consistent with that intention (e.g., actual pressing); and (c) an expected, temporally contiguous sensory effect (e.g., hearing a tone).

Intentional binding has been shown to vary inter-personally. For example, those who suffer from autistic spectrum disorder evince reduced binding, relative to healthy participants (Sperduti et al. 2013). Just the opposite occurs in those who suffer from schizophrenia or in those who have taken ketamine, which when taken at subanesthetic levels causes a state that resembles schizophrenia in certain respects (Moore and Obhi 2012, pp. 554, 555). In effect, those who have passivity experiences belong to a subset of persons who experience "hyper-binding"-actions and their consequences are experienced as even more tightly bound in time than are the actions and consequences of healthy persons who experience intentional binding.

\footnotetext{
${ }^{11}$ Binding comprises both a predictive and a retrospective mechanism; schizophrenia is associated with an impairment to the former (Voss et al. 2010).
} 
Fig. 5 Principle of confounded expectations: the case of alien actions

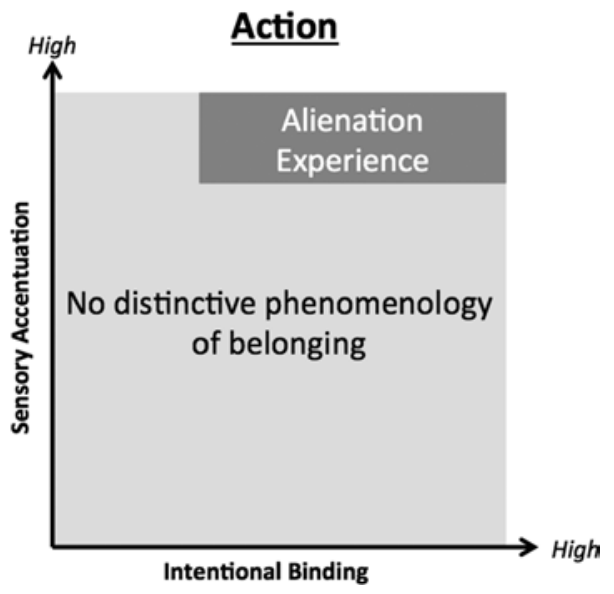

What appears to be the case with passivity experiences then is the reverse of what occurs in pain asymbolia. In pain asymbolia, expectations are confounded because something is missing. In passivity experiences, something is added.

For passivity experiences, the feeling that our actions are under the control of some "external force" results when we feel what we should not feel (Frith 2005, p. 753). In ordinary actions sensory attenuation occurs, but here attenuation fails; instead, proprioceptive and somatosensory sensations are heightened. When a person reports that his grandfather is moving his foot up and down, or that a computer inserted into his brain is causing him to turn right or left, because intentional binding applies to both self and others, a sense that observed behaviors are agentive is retained. What differs is the added awareness of the sensory consequences of those actions.

Figure 5 depicts this relationship. Whereas in the normal case sensory attenuation should occur, here sensory accentuation occurs. This is indicated by the $y$-axis. The $x$-axis indicates intentional binding, a robust correlate of agency. And since those most likely to have passivity experiences also evince hyper-binding, we can expect that their temporal linking of behavior to its consequences is even stronger than it is for healthy persons. Here, because an atypical mental cluster is realizedsensory accentuation and hyper-binding - a POB in the form of an alienation experience occurs.

Since the attribution of agency is not self-specific, here too we require a $z$-dimension, just as with Fig. 3. Indeed it is the case that there is some evidence that anterior regions of the CMS are involved in the personal experience of agency, especially the anterior cingulate and the medial prefrontal cortex (Northoff and Bermpohl 2004, pp. 102, 103). Accordingly, an adequate explanation of alien actions would seem to require both personal and sub-personal levels: sensory accentuation, hyperbinding, SRP in the anterior CMS, and (see Fig. 4) MA of this bizarre clustering of mental states. 
It is not clear whether there are any action-related phenomena that would correspond to the "familiar" or "other" processing indicated in Fig. 3, though the model implies this empirical possibility. ${ }^{12}$ But the model, along with some recent investigations and descriptions of other schizophrenic symptoms, suggest that perhaps all passivity experiences can be treated within the framework adumbrated here. Whereas most prior research has focused on agency for action (cf. Frith 2005, p. 753), recent experimental investigations have begun attending to the sense of agency for thought (Swiney and Sousa 2013).

There is some evidence to suggest that thought insertions too are accompanied by vivid sensory experiences. Cahill and Frith (1996, p. 278), for example, report that "one of our patients reported physically feeling the alien thoughts as they entered his head and claimed that he could pin-point the point of entry!"13 Indeed, Mullins and Spence (2003, p. 295) record that thought insertions "in some (if not all) patients...can incorporate abnormalities of perception." These clinical reports and the explanatory framework adopted here suggest that perhaps passivity experiences in general are characterized by vivid sensory experiences. Such experiences serve as a phenomenological marker of alien agency.

The scope of this hypothesis could be further tested by assessment of the callosal type of anarchic (or, wayward) hand syndrome, which typically results from damage to the anterior corpus callosum (Uddin 2011, p. 97; Verleger et al. 2011). As Marcel (2003, p. 81) has written, for those afflicted with anarchic hand, "there is a positive otherness to the anarchic actions." Although the anarchic hand, usually the left, does seem to execute goal-directed movements, patients do not experience these actions as regulated by self. This "otherness" can even be extreme to the point of allowing for inter-manual conflict: for example, a patient puts clothes on with the right hand, while pulling them off with the left (Aboitiz et al. 2003, p. 253; cf., Barbeau et al. 2004).

Anarchic hand does differ from passivity experiences in at least one respect: the alien actions of schizophrenics tend to be attributed to a distinct agent, whereas the alien actions performed by those with wayward hands are not. Although anarchic hands evince contrariness, seemingly a mind of their own, still these patients are not inclined to ascribe those actions to a specific agent. Since the patients lack access to the intentions which motivate actions of the anarchic hands (e.g., Miller et al. 2010), perhaps that is sufficient to explain the experience of "otherness." But lacking access to intention does not entail that patients will experience otherness, and in fact when the central thalamic nucleus is electrically stimulated causing movements that patients describe as goal-directed and voluntary, they simply say they do not know

\footnotetext{
12 Perhaps the contents of auditory hallucinations, however, are explainable in such terms (Lane and Northoff 2012). Auditory hallucinations can be the sound of one's own voice, as in "thought broadcast" (Pawar and Spence 2003), or they could be the voices of someone familiar or someone unknown (David 2004). The model proposed here suggests that the difference among these three types might be due to self-related processing. For a novel hypothesis of auditory verbal hallucinations that touches upon some related issues, see, Northoff and Qin (2011) and Northoff (2013a, p. 349).

${ }^{13}$ Italics not contained in original.
} 
why they made those movements (Marcel 2003, pp. 72-73). ${ }^{14}$ They do not report experiencing "otherness."

The framework developed here suggests that to the extent that those who experience anarchic hand describe those actions as alien, those patients should also report sensory accentuation. Since they do not suffer from schizophrenia, and thereby, are unlikely to experience hyper-binding, the degree to which their actions are felt to be alien are unlikely to be as vivid as the actions of those who suffer from passivity experiences. But if damage to the anterior corpus callosum does not interfere with SRP, their anarchic actions should correlate with sensory accentuation. If a governing principle of the phenomenology of actions is to be found, it is this: actions are silent unless they are alien.

\section{Conclusion}

The model depicted in Fig. 4 is still but a toy model. Among other things, in order to make it more comprehensive I have reduced MSC to just one dimension, and prior to that I treated the clustering of mental states as reducible to two dimensions. Even when discussing action, I considered no more than two dimensions-intentional binding and sensory accentuation. But this simplification is nothing more than a heuristic; the confounding of expectations is not likely to be reducible to so few dimensions. A completed model of belonging, or mental glue, will include more than just the dimensions limned here. If the ideas developed previously approximate the truth, they are just a point of departure, not an endpoint.

In the case of action, further attempts to understand alienation will include testing the hypotheses proffered previously. Is it the case that anarchic actions are experienced as anarchic because of an MA of sensory accentuation and intentional binding that are accompanied by SRP? Is it also the case that thought insertion is like other forms of passivity experience, in which it is accompanied by heightened sensory activity? The model and strands of data pieced together from various case studies or experimental investigations suggest as much. But obviously, the evidence adduced here on behalf of these hypotheses falls far short of confirmation.

The search for further confirmation is worth pursuing though, not only because it might enhance our understanding of these pathologies. Beyond that, it might also assist with the development of this toy model into a more mature version of greater scope that can guide research into previously unanticipated domains, which is after all one of the marks of a good theory. There is always risk in such an approach, not least of which is the concern that we might be committing what can be dubbed the "natural kinds fallacy." Perhaps, the phenomena described previously are only

\footnotetext{
${ }^{14}$ Marcel does observe that it is possible that stimulation of the thalamus causes both the action and an intention, but patients never reported an "urge to do the action." This leaves only the possibility that an unconscious intention was triggered by the stimulus, but there is no evidence to support this claim.
} 
superficially similar, no more alike than are gold and iron pyrite. Similarity of subjective report does not entail that the phenomena can all be treated from within a unified framework. But the claim advanced here is that we already have sufficient evidence of a suggestive sort, sufficient to warrant further investigation. And a virtue of the model presented here is that it does generate testable hypotheses, which will stand or fall, depending upon the results of clinical or experimental investigations.

One reason for cautious optimism that this model or some more mature version of it will stand the test of time, is that it is consistent with many developing theories of conscious experience that advocate a deflationary view of its functional role, a view that is compelling because much evidence has accumulated to show that consciousness is slow, capable of just a limited capacity, and unnecessary for many perceptual and cognitive activities (Churchland 2002, pp. 127-200; Edelman et al. 2011; Koch 2004, pp. 205-229; Rosenthal 2008). Rather than becoming involved in the quotidian, consciousness seems much better suited to dealing with novelty or error, and indeed "the unexpected has an especially privileged change of 'gaining access' to consciousness" (Gray 2004, p. 76). As regards the issue at hand, "the unexpected" is constituted by the way in which self-related, atypical clustering of mental states confounds expectations.

How are these seeming limits to consciousness related to experiences of self? They suggest that many who explore this terrain are in error from the get-go. Craig (2009, p. 65), for example, writes: "I regard awareness as knowing that one exists (the feeling that ' $I \mathrm{am}$ '); an organism must be able to experience its own existence as a sentient being before it can experience the existence and salience of anything else in the environment." ${ }^{15}$ The considerations adduced here and elsewhere (Lane 2012) suggest that there is no "feeling that 'I am'," at least that is if this is literally taken to be a condition for experiencing "the existence and salience of anything else in the environment." To repeat just one among the reasons cited above: consciousness is slow. If we had to wait for a "feeling that I am," that wait would be an obstacle to experiencing the existence and salience of anything else.

We do reflect on self. Some of us do this more; some, less. But this is when we can extract ourselves from the hustle and bustle of daily life, and it is not likely well construed as an experience of self, for these reflections do not seem to involve or require any obvious sensory experiences. A contention of this essay is that our most direct conscious access to self in the nonce is when we become aware of its absence. Ordinarily SRP takes place on a sub-personal level, out-of-sight, so to speak. It is only when we become aware of self-related mental states clustering in bizarre ways that we become, indirectly, aware of self. And if we wish to learn about self, we would be well advised to attend closely to these absences.

Acknowledgments I express my heartfelt gratitude to Ellie Hua Wang and to Tzu-Wei Hung for their constructive comments on previous versions of this manuscript. For much useful discussion, I am also grateful to the many other participants in Academia Sinica's International Conference on Language and Action, Taipei, Taiwan (September 17-18, 2013). Funding for this research was, in part, provided by National Science Council of Taiwan research grants, 100-2410-H-038-009-MY3 and 102-2420-H-038-001-MY3.

${ }^{15}$ Italics not contained in the original. 


\section{References}

Aboitiz, F., Carrasco, X., Schröter, C., Zaidel, D., Zaidel, E., \& Lavados, M. (2003). The alien hand syndrome: Classification of forms reported and discussion of a new condition. Neurological Sciences, 24(4), 252-257.

Auvray, M., Myin, E., \& Spence, C. (2010). The sensory-discriminative and affective-motivational aspects of pain. Neuroscience \& Biobehavioral Reviews, 34(2), 214-223.

Baars, B. J. (2007). Attention and consciousness. In B. J. Baars \& N. M. Gage (Eds.), Cognition, brain, and consciousness, second edition: Introduction to cognitive neuroscience (pp. 225 254). New York: Academic Press.

Baars, B. J., Ramsøy, T. Z., \& Laureys, S. (2003). Brain, conscious experience and the observing self. Trends in Neurosciences, 26(12), 671-675.

Barbeau, E., Joubert, S., \& Poncet, M. (2004). A single case-study of diagnostic dyspraxia. Brain and Cognition, 54(3), 215-217.

Bayne, T. (2010). The unity of consciousness. New York: Oxford University Press.

Bayne, T. (2011). The sense of agency. In F. Macpherson (Ed.), The senses: Classic and contemporary philosophical perspectives (pp. 355-374). New York: Oxford University Press.

Berthier, M., Starkstein, S., \& Leiguarda, R. (1988). Asymbolia for pain: A sensory-limbic disconnection syndrome. Annals of Neurology, 24, 41-49.

Blakemore, S.-J., Frith, C. D., \& Wolpert, D. M. (1999). Spatio-temporal prediction modulates the perception of self-produced stimuli. Journal of Cognitive Neuroscience, 11(5), 551-559.

Blakemore, S.-J., Frith, C. D., \& Wolpert, D. M. (2000a). Why can't you tickle yourself? NeuroReport, 11, R11-R16.

Blakemore, S.-J., Smith, J., Steel, R., Johnstone, E., \& Frith, C. (2000b). The perception of selfproduced sensory stimuli in patients with auditory hallucinations and passivity experiences: Evidence for a breakdown of self-monitoring. Psychological Medicine, 30(5), 1131-1139.

Bor, D. (2012). The ravenous brain: How the new science of consciousness explains our insatiable search for meaning. New York: Basic Books.

Bortolotti, L. (2010). Delusions and other irrational beliefs. New York: Oxford University Press.

Cahill, C., \& Frith, C. (1996). False perceptions or false beliefs? Hallucinations and delusions in schizophrenia. In P. W. Halligan \& J. C. Marshall (Eds.), Method in madness: Case studies in cognitive neuropsychiatry (pp. 267-291). New York: Psychology Press.

Carruthers, P. (2000). Phenomenal consciousness: A naturalistic theory. New York: Cambridge University Press.

Churchland, P. S. (2002). Brain-wise: Studies in neurophilosophy. Cambridge: The MIT Press.

Clark, A., Anderson, M. L., Block, N., Bowman, H., Bridgeman, B., Buckingham, G., et al. (2013). Whatever next? Predictive brains, situated agents, and the future of cognitive science. Behavioral and Brain Sciences, 36(3), 181-204.

Craig, A. D. (2009). How do you feel-now? The anterior insula and human awareness. Nature Reviews: Neuroscience, 10(1), 59-70.

Crick, F., \& Koch, C. (2003). A framework for consciousness. Nature Neuroscience, 6(2), 119-126.

David, A. S. (2004). The cognitive neuropsychiatry of auditory verbal hallucinations: An overview. Cognitive Neuropsychiatry, 9(1/2), 107-123.

Davies, M. (2000). Interaction without reduction: The relationship between personal and subpersonal levels of description. Mind \& Society, 1(2), 87-105.

de Pinedo-Garcia, M., \& Noble, J. (2008). Beyond persons: Extending the personal/subpersonal distinction to non-rational animals and artificial agents. Biology and Philosophy, 23(1), 87100.

Edelman, G. M., Gally, J. A., \& Baars, B. J. (2011). Biology of consciousness. Frontiers in Psychology, 2, 1-7.

Ellis, H. D., \& Lewis, M. B. (2001). Capgras delusion: A window on face recognition. Trends in Cognitive Sciences, 5(4), 149-156. 
Feinberg, T. E. (2009). From axons to identity: Neurological explorations of the nature of the self. New York: W. W. Norton.

Fitzgibbon, B. M., Giummarra, M. J., Georgiou-Karistianis, N., Enticott, P. G., \& Bradshaw, J. L. (2010). Shared pain: From empathy to synaesthesia. Neuroscience and Biobehavioral Reviews, $34(4), 500-512$.

Frith, C. (2005). The self in action: Lessons from delusions of control. Consciousness and Cognition, 14(4), 752-770.

Frith, C. D., Blakemore, S.-J., \& Wolpert, D. M. (2000). Explaining the symptoms of schizophrenia: Abnormalities in the awareness of action. Brain Research Reviews, 31(2/3), 357-363.

Friston, K. (2009). The free-energy principle: A rough guide to the brain? Trends in Cognitive Science, 13(7), 293-301.

Gallagher, S. (2012). First-person perspective and immunity to error through misidentification. In S. Miguens \& G. Preyer (Eds.), Consciousness and subjectivity (pp. 187-214). Heusenstamm: Ontos.

Grahek, N. (2007). Feeling pain and being in pain (2nd ed.). Cambridge: The MIT Press.

Gray, J. (2004). Consciousness: Creeping up on the hard problem. New York: Oxford University Press.

Haggard, P., Clark, S., \& Kalogeras, J. (2002). Voluntary action and conscious awareness. Nature Neuroscience, 5(4), 382-385.

Hempel, C. G. (1965). Aspects of scientific explanation and other essays in the philosophy of science. New York: The Free Press.

Hirjack, D., \& Fuchs, T. (2010). Delusions of technical alien control: A phenomenological description of three cases. Psychopathology, 43(2), 96-103.

Hohwy, J. (2013). The predictive mind. New York: Oxford University Press.

Jones, E. G. (2007). The thalamus (2nd ed.). New York: Cambridge University Press.

Klein, S. B. (2013a). The two selves: Their metaphysical commitments and functional independence. New York: Oxford University Press.

Klein, S. B. (2013b). Making the case that episodic recollection is attributable to operations occurring at retrieval rather than to content stored in a dedicated subsystem of long-term memory. Frontiers in Behavioral Neuroscience, 7(3), 1-14. doi:10.3389/fnbeh.2013.00003.

Klein, S. B., \& Nichols, S. (2012). Memory and the sense of personal identity. Mind, 121(483), $677-702$.

Koch, C. (2004). The quest for consciousness: A neurobiological approach. Englewood: Roberts and Company.

Kühn, S., Brass, M., \& Haggard, P. (2013). Feeling in control: Neural correlates of experience of agency. Cortex, 49(7), 1935-1942.

Lane, T. (2012). Toward an explanatory framework for mental ownership. Phenomenology and the Cognitive Sciences, 11(2), 251-286.

Lane, T., \& Liang, C. (2008). Higher-order thought and the problem of radical confabulation. Southern Journal of Philosophy, 46(1), 69-98.

Lane, T., \& Liang, C. (2010). Mental ownership and higher-order thought. Analysis, 70(3), 496501.

Lane, T., \& Liang, C. (2011). Self-consciousness and immunity. Journal of Philosophy, 108(2), $78-99$.

Lane, T., \& Northoff, G. (2012, July). Mineness, Minimal Self, and Self-Related Processing. Paper presented at the 16th Annual Meeting of the Association for the Scientific Study of Consciousness. Brighton, UK.

Lane, T., Yeh, S., \& Chang, A. (2013, July). Switching Attention to the Rubber Hand. Paper presented at the 17th Annual Meeting of the Association for the Scientific Study of Consciousness, San Diego, CA.

Lau, H., \& Rosenthal, D. (2011). Empirical support for higher-order theories of conscious awareness. Trends in Cognitive Sciences, 15(8), 365-373. 
Marcel, A. (2003). The sense of agency: Awareness and ownership of action. In J. Roessler \& N. Eilan (Eds.), Agency and self-awareness: Issues in philosophy and psychology (pp. 48-93). Oxford: Clarendon.

Martin, J.-R., \& Pacherie, E. (2013). Out of nowhere: Thought insertion, ownership and contextintegration. Consciousness and Cognition, 22(1), 111-122.

McDowell, J. (1994). Mind and world. Cambridge: Harvard University Press.

Mellor, C. S. (1970). First-rank symptoms of schizophrenia. British Journal of Psychiatry, $117(536), 15-23$.

Metzinger, T. (2003). Being no one: The self-model theory of subjectivity. Cambridge: The MIT Press.

Miller, M. B., Sinnott-Armstrong, W., Young, L., King, D., Paggi, A., Fabri, M., et al. (2010). Abnormal moral reasoning in complete and partial callosotomy patients. Neuropsychologia, 48(7), 2215-2220.

Moore, J. W., \& Obhi, S. S. (2012). Intentional binding and the sense of agency: A review. Consciousness and Cognition, 21(1), 546-561.

Moore, J. W., Teufel, C., Subramaniam, N., Davis, G., \& Fletcher, P. C. (2013). Attribution of intentional causation influences the perception of observed movements: Behavioral evidence and neural correlates. Frontiers in Psychology, 4, 23. doi:10.3389/fpsyg.2013.00023.

Mullins, S., \& Spence, S. A. (2003). Re-examining thought insertion: Semi-structured literature review and conceptual analysis. British Journal of Psychiatry, 182, 293-298.

Nordgaard, J., Arnfred, S. M., Handest, P., \& Parnas, J. (2008). The diagnostic status of first rank symptoms. Schizophrenia Bulletin, 34(1), 137-154.

Northoff, G. (2013a). Unlocking the brain: Vol. 2. Consciousness. New York: Oxford University Press.

Northoff, G. (2013b). Unlocking the brain: Vol. 1. Coding. New York: Oxford University Press.

Northoff, G., \& Bermpohl, F. (2004). Cortical midline structures and the self. Trends in Cognitive Sciences, 8(3), 102-107.

Northoff, G., \& Panksepp, J. (2008). The trans-species concept of self and the subcortical-cortical midline system. Trends in Cognitive Science, 12(7), 259-264.

Northoff, G., \& Qin, P. (2011). How can the brain's resting state activity generate hallucinations? A "resting state hypothesis" of auditory verbal hallucinations. Schizophrenia Research, 127, 202-214.

Northoff, G., Lane, T., \& Yen, N. (2014). Pre-stimulus neural activity predicts self-relatedness judgments in healthy subjects: A multi-modal study. Unpublished manuscript.

Pacherie, E. (2011). Self-agency. In S. Gallagher (Ed.), The Oxford handbook of the self (pp. 442 464). Oxford: Oxford University Press.

Pawar, A. V., \& Spence, S. A. (2003). Defining thought broadcast: Semi-structured literature review. British Journal of Psychiatry, 183, 287-291.

Prinz, J. (2012a). Waiting for the self. In J.-L. Liu \& J. Perry (Eds.), Consciousness and the Self: New essays (pp. 123-149). New York: Cambridge University Press.

Prinz, J. (2012b). The conscious brain: How attention engenders experience. New York: Oxford University Press.

Obhi, S. S., \& Hall, P. (2011). Sense of agency and intentional binding in joint action. Experimental Brain Research, 211(3/4), 655-662.

Ochsner, K. N., Zaki, J., Hanelin, J., Ludlow, D. H., Knierim, K., Ramachanran, T., et al. (2008). Your pain or mine? Common and distinct neural systems supporting the perception of pain in self and other. Social Cognitive and Affective Neuroscience, 3(2), 144-160.

Qin, P., \& Northoff, G. (2011). How is our self related to midline regions and the default-mode network? NeuroImage, 57(3), 1221-1233.

Raichle, M. E. (2010). Two views of brain function. Trends in Cognitive Science, 14(4), 180-190.

Rosenthal, D. M. (2002). Explaining consciousness. In D. J. Chalmers (Ed.), Philosophy of mind: Classical and contemporary readings (pp. 406-421). New York: Oxford University Press.

Rosenthal, D. M. (2005). Consciousness and mind. New York: Oxford University Press.

Rosenthal, D. M. (2008). Consciousness and its function. Neuropsychologia, 46(3), 829-840. 
Sass, L. A., \& Parnas, J. (2003). Schizophrenia, consciousness, and the self. Schizophrenia Bulletin, 29(3), 427-444.

Schooler, J. W., Smallwood, J., Christoff, K., Handy, T. C., Reichle, E. D., \& Sayette, M. A. (2011). Meta-awareness, perceptual decoupling and the wandering mind. Trends in Cognitive Science, 15(7), 319-326.

Seth, A. K., Suzuki, K., \& Critchley, H. D. (2012). An interoceptive predictive coding model of conscious presence. Frontiers in Psychology, 2, 395.

Shea, N. (2013). Neural mechanisms of decision-making and the personal level. In K. W. M. Fulford, M. Davies, R. G. T. Gipps, G. Graham, J. Z. Sadler \& G. Stanghellini (Eds.), The Oxford handbook of philosophy and psychiatry (pp. 1063-1082). New York: Oxford University Press.

Shoemaker, S. (1994). Self-knowledge and "inner Sense": Lecture I: The object perception model. Philosophy and Phenomenological Research, 54(2), 249-269.

Sierra, M. (2009). Depersonalization: A new look at a neglected syndrome. New York: Cambridge University Press.

Sorensen, R. (2007). The vanishing point: A model of the self as an absence. Monist, 90(3), 432-456.

Sperduti, M., Pieron, M., Leboyer, M., \& Zalla, T. (2013, July 24). Altered pre-reflective sense of agency in autism spectrum disorders as revealed by reduced intentional binding. Journal of Autism and Developmental Disorders, 44(2), 343-352. doi:10.1007/s10803-013-1891-y. (http:// link.springer.com/article/10.1007/s10803-013-1891-y.)

Stephens, G. L., \& Graham, G. (2000). When self-consciousness breaks: Alien voices and inserted thoughts. Cambridge: The MIT Press.

Stone, J. L., \& Goodrich, J. T. (2006). The craniopagus malformation: Classification and implications for surgical separation. Brain, 129(5), 1084-1095.

Swiney, L., \& Sousa, P. (2013). When our thoughts are not our own: Investigating agency misattribution using the Mind-to-Mind paradigm. Consciousness and Cognition, 22(2), 589-602.

Tsakiris, M., Schütz-Bosbach, S., \& Gallagher, S. (2007). On agency and body-ownership: Phenomenological and neurocognitive reflections. Consciousness and Cognition, 16(3), 645-660.

Uddin, L. Q. (2011). Brain connectivity and the self: The case of cerebral disconnection. Consciousness and Cognition, 20(1), 94-98.

Verleger, R., Binkofski, F., Friedrich, M., Sedlmeier, P., \& Kömpf, D. (2011). Anarchic-hand syndrome: ERP reflections of lost control over the right hemisphere. Brain and Cognition, 77(1), $138-150$.

Voss, M., Moore, J., Hauser, M., Gallinat, J., Heinz, A., \& Haggard, P. (2010). Altered awareness of action in schizophrenia: A specific deficit in predicting action consequences. Brain, 133(10), 3104-3112.

Wegner, D. (2002). The illusion of conscious will. Cambridge: The MIT Press.

Wohlschläger, A., Haggard, P., Gesierich, B., \& Prinz, W. (2003). The perceived onset time of selfand other-generated actions. Psychological Science, 14(6), 586-591.

Zahn, R., Talazko, J., \& Ebert, D. (2008). Loss of the sense of self-ownership for perceptions of objects in a case of right inferior temporal, parieto-occipital and precentral hypometabolism. Psychopathology, 41(6), 397-402.

Zihl, J., von Cramon, D., \& Mai, N. (1983). Selective disturbance of movement vision after bilateral brain damage. Brain, 106(2), 313-340. 